\title{
Photosynthetic enhancement, lifespan extension, and leaf area enlargement in flag leaves increased the yield of transgenic rice plants overproducing Rubisco under sufficient $\mathbf{N}$ fertilization
}

\author{
Marin Tanaka \\ Tohoku University \\ Mamoru Keira \\ Tohoku University \\ Dong-Kyung Yoon \\ Tohoku University \\ Tadahiko Mae \\ Tohoku University \\ Hiroyuki Ishida \\ Tohoku University \\ Amane Makino \\ Tohoku University \\ Keiki Ishiyama ( $\nabla$ keiki.ishiyama.e5@tohoku.ac.jp) \\ Tohoku University
}

\section{Research Article}

Keywords: Canopy architecture, Flag leaf, Grain yield, Lifespan, light-reception, Nitrogen, Photosynthesis, RBCS-sense rice plants, Rubisco

Posted Date: December 6th, 2021

DOI: https://doi.org/10.21203/rs.3.rs-1139533/v1

License: (c) (1) This work is licensed under a Creative Commons Attribution 4.0 International License. Read Full License

Version of Record: A version of this preprint was published at Rice on February 9th, 2022. See the published version at https://doi.org/10.1186/s12284-022-00557-5. 


\section{Abstract}

Background: Improvement in photosynthesis is one of the most promising approaches to increase grain yields in crop plants. In our previous research using an isolated experimental paddy field, transgenic rice plants overproducing Rubisco by $30 \%$ (RBCS-sense rice plants) showed up to $28 \%$ increase in grain yields under sufficient nitrogen $(\mathrm{N})$ fertilization. Furthermore, the plant $\mathrm{N}$ contents above-ground sections and Rubisco contents of the flag leaves were higher in the RBCS-sense rice plants than the wild-type rice plants during the ripening period, which may be reasons for the increased yields.

Result: In this research, the photosynthetic capacity and canopy architecture were analyzed to explore factors for the increased yields of $R B C S$-sense rice plants. It was found that $\mathrm{N}$ had already been preferentially distributed into the flag leaves at the early ripening stage, contributing to maintaining higher Rubisco content levels in the enlarged flag leaves and extending the lifespan of the flag leaves of RBCSsense rice plants throughout ripening periods under sufficient $\mathrm{N}$ fertilization. The higher amounts of Rubisco also improved the photosynthetic activity in the flag leaves throughout the ripening period. Although the enlarged flag leaves of the RBCS-sense rice plants occupied large spatial areas of the uppermost layer in the canopy, no significant prevention of light penetration to leaves below the flag leaves was observed. Additionally, since the $\mathrm{CO}_{2}$ assimilation rates of lower leaves between wild-type and $R B C S$-sense rice plants were the same at the early ripening stage, the lower leaves did not contribute to an increase in yields between the two genotypes.

Conclusion: It was concluded that improvements in the photosynthetic capacity by higher leaf $\mathrm{N}$ and Rubisco contents, enlarged the leaf area, and extended the lifespan of flag leaves, causing an increase in grain yields of $R B C S$ sense rice plants grown under sufficient $\mathrm{N}$ fertilization.

\section{Background}

By 2050, the world's population is expected to reach 10 billion, and the United Nations Food and Agricultural Organization has predicted that the world population will need 70\% more food (Long 2012). The rice yield increases after the "green revolution" depended mainly on the development of semi-dwarf cultivars with a greater harvest index and greatly increased $\mathrm{N}$ fertilizer application (Yoshida 1981, Evans 1998). This strategy is reaching its limits. Excess application of $\mathrm{N}$ fertilizer causes environmental pollution, including acid rain and the eutrophication of rivers and oceans (Canfield et al. 2010, Good and Beaty, 2011). Further enhancement of grain yield must be by increasing total biomass accumulation without increased $\mathrm{N}$ fertilizer inputs (Makino 2011). Improving photosynthesis performance is the most promising approach to meet this challenge (von Caemmerer and Evans 2010, Long et al. 2015, Makino 2021).

Ribulose-1,5-bisphosphate carboxylase-oxygenase (Rubisco) (EC 4.1.1.39) catalyzes $\mathrm{CO}_{2}$ fixation during photosynthesis, and the production of 2-phosphoglycolate in the photorespiratory pathway, and the amount of Rubisco is considered a rate-limiting factor for carbon fixation under current atmospheric 
$\mathrm{CO}_{2}$ and $\mathrm{O}_{2}$ concentrations as well as saturating light (Makino et al. 1985). In our previous research, transgenic rice plants (RBCS-sense rice plants, line Sr-26-8) with approximately 30\% overproducing Rubisco compared to the wild-type was produced by transforming Rubisco small subunit2 (OsRBCS2, RAP-DB id; Os12g0274700) complementary DNA with a sense direction (Suzuki et al. 2007). The RBCS sense rice plants indicated that grain yields were increased up to $28 \%$ compared to wild-type plants in the isolated experimental paddy field under sufficient $\mathrm{N}$ fertilization (Yoon et al. 2020). Furthermore, the $\mathrm{N}$ contents of the above-ground sections and Rubisco contents in the flag leaves in RBCS-sense plants were higher than the wild-type rice plants during ripening periods, which may be reasons for higher yields (Yoon et al. 2020). However, a few unclear points remained, such as contributions of photosynthesis of leaves below the flag leaves by the light-reception in the canopy to the yield of the RBCS-sense rice plants.

This research investigated the photosynthetic capacity of leaves existing during the ripening period and their light-reception by analyzing canopy architecture using the stratified cutting method to identify factors affecting photosynthesis that led to increased grain yields of the RBCS-sense rice plants. It was found that $\mathrm{N}$ had already been preferentially distributed into the flag leaves of the RBCS-sense rice plant at the early ripening stage. The greater $\mathrm{N}$ distribution to the flag leaves appeared to improve the photosynthetic capacity by the increase in Rubisco content, enlarged leaf area, and extended the lifespan of the flag leaves in the RBCS-sense rice plants. Here the effects of these physiological and architectural changes of RBCS-sense rice plants on the yield were discussed.

\section{Results}

\section{Total dry matter production and brown rice yield of the RBCS-sense rice plants}

Table 1 indicates total dry matter production of above-ground sections, brown rice yields per unit land area, and yield components of the wild-type and RBCS-sense rice plants. In the plots under $15 \mathrm{~g} \mathrm{~N} \mathrm{~m}^{-2}$ fertilization, total dry matter production and brown rice yield of RBCS-sense plants showed a $10 \%$ and $16 \%$ increase compared to wild-type rice plants, respectively ( $t$-test; $p=0.005$ and $p=0.001$, respectively) (Table 1). The weight of the single brown rice and the ratio of filled spikelets were $5 \%$ and $6 \%$ higher in $R B C S$ sense plants than in wild-type rice plants, respectively ( $t$-test; $p=0.001$ and $p=0.000$, respectively) (Table 1). Total spikelet numbers were not significantly different between the two genotypes ( $t$-test; $p=$ 0.216) (Table 1). These results showed that the increased grain yield was caused by a higher ratio of filled spikelets and single weight of brown rice. In contrast, in cultivation plots applied with $8 \mathrm{~g}$ and $0 \mathrm{~g} \mathrm{~N}$ $\mathrm{m}^{-2}$ fertilizer, no increase in total dry matter production of $R B C S$-sense was observed, and the brown rice yield was significantly lower in $R B C S$-sense rice plants in the $0 \mathrm{~g} \mathrm{~N} \mathrm{~m}^{-2}$ plot ( $t$-test; $p>0.05$, respectively) (Table 1). Similar results were observed in our previous report (Yoon et al. 2020).

High photosynthetic capacity in flag leaves of RBCS-sense rice plants throughout ripening period under sufficient $\mathrm{N}$ fertilization 
In this research, the ripening period was divided into three stages and is defined as follows: early as from the heading date to 17 days after heading $(\mathrm{DAH})$, middle as from 18 to $34 \mathrm{DAH}$, and late ripening stage from 35 to the harvesting date. The $\mathrm{CO}_{2}$ assimilation rates per unit leaf area were measured in the flag leaves and penultimate leaves (leaves just below flag leaves) in wild-type and RBCS-sense rice plants at one and four DAH, respectively, in the early ripening stage (Fig. 1). The $\mathrm{CO}_{2}$ assimilation rates in flag leaves were about $18 \%$ higher in the RBCS-sense than in the wild-type rice plants under strong light conditions as $1500 \mu \mathrm{mol}$ quanta $\mathrm{m}^{-2} \mathrm{~s}^{-1}$ (t-test; $p=0.029$ ) (Fig. 1A). In other light conditions as 1000, 500 , and $100 \mu \mathrm{mol}$ quanta $\mathrm{m}^{-2} \mathrm{~s}^{-1}$, the $\mathrm{CO}_{2}$ assimilation rates of the RBCS-sense tented to be higher than that of wild-type plants, while there were no significant differences ( $t$-test; $p=0.061$ at $1000, p=0.283$ at 500 , and $p=0.514$ at $100 \mu \mathrm{mol}$ quanta $\mathrm{m}^{-2} \mathrm{~s}^{-1}$, respectively) between two genotypes (Fig. $1 \mathrm{~A}$ ). In contrast, there were no obvious differences in the $\mathrm{CO}_{2}$ assimilation rates of the penultimate leaves between wild-type and $R B C S$ sense rice plants (t-test; $p>0.05$, respectively) (Fig. 1B).

The atmosphere $\mathrm{CO}_{2}$ concertation in the canopy of the $R B C S$ sense rice plants applied with $0 \mathrm{~g}$ and $15 \mathrm{~g}$ $\mathrm{N} \mathrm{m}^{-2} \mathrm{~N}$ fertilizer were measured from -26 to $35 \mathrm{DAH}$ as reproductive (panicle formation) and ripening periods. The atmospheric $\mathrm{CO}_{2}$ concentrations in the $15 \mathrm{~g} \mathrm{~N} \mathrm{~m}^{-2}$ plot were lower than in the $0 \mathrm{~g} \mathrm{~N} \mathrm{~m}^{-2}$ plot throughout the reproduction period, with a maximum depletion of $70 \mu \mathrm{mol} \mathrm{mol}^{-1}$, showing that photosynthesis was more active in the $15 \mathrm{~g} \mathrm{~N} \mathrm{~m}^{-2}$ plot than in the $0 \mathrm{~g} \mathrm{~N} \mathrm{~m}^{-2}$ plot (Fig. 2A).

Total N, Rubisco, and chlorophyll (Chl) contents in the flag and penultimate leaves were measured from 4-8 DHA early, from 26-30 DAH in the middle, and 47 DAH in the late ripening stages. The amounts of Rubisco per unit land area in the flag leaves of the RBCS-sense rice plants were about $76 \%-150 \%$ higher than the wild-type rice plants throughout the ripening period, although there were no significant differences in Rubisco contents between the two genotypes at the middle ripening period ( $t$-test; $p=0.004$ at early, $p=0.058$ at the middle, and $p=0.003$ at late ripening stages) (Fig. 2B). In the penultimate leaves, there were no differences in Rubisco contents at the early and middle ripening stages between the two genotypes ( $t$-test; $p>0.05$, respectively) (Fig. 2B). Total nitrogen and $\mathrm{Chl}$ contents also exhibited similar trends to Rubisco contents in the flag leaves and penultimate leaves between two genotypes (Figs. 2C, D). The total $\mathrm{N}$ contents in the flag leaves of RBCS-sense plants were higher by $38 \%-101 \%$ compared to those of wild-type rice plants (t-test; $p=0.023$ at early, $p=0.049$ at the middle, and $p=0.002$ at late ripening stages), although those in penultimate leaves were almost the same levels ( $t$-test; $p>0.05$, respectively) at the early and middle ripening stages (Fig. $2 \mathrm{C}$ ). The Chl contents in the flag leaves of $R B C S$ sense plants were higher by $34 \%-103 \%$ compared to those of wild-type rice plants ( $t$-test; $p=0.041$ at early and $p=0.002$ at late ripening stages), although there were no significant differences at the middle ripening stage ( $t$-test; $p=0.056)$. There were almost the same levels of $\mathrm{Chl}$ contents in the penultimate leaves between two genotypes at the early and middle ripening stages ( $t$-test; $p>0.05$, respectively) (Fig. 2D). At the late ripening stage, the penultimate leaves were dead and in no measurable conditions (Figs. 2B-D). 


\section{No difference in light extinction in the canopies between wild-type and RBCS-sense rice plants at the early ripening stage}

This current research showed that changes in total dry matter of above-ground sections (shoots) on 10 DAH in the early (Figs. 3A, B) and $49 \mathrm{DAH}$ in late ripening stages (Figs. 3C, D) of the wild-type and RBCS sense rice plants were of similar trends to the previous research; there were no differences ( $t$-test; $p=$ 0.135) in the total dry matter between two genotypes at the early ripening, but at the late ripening stage, there were significant differences ( $t$-test; $p=0.001$ ) (Yoon et al. 2020, Supplementary File 1: Figure S1). However, the stratified cutting analyses of this research found differences in canopy architecture, i.e., organ-specific dry weight along the vertical axis, between two genotypes from the early ripening stage. Three sets of samples comprised four neighboring hills with an average number of stems or panicles of wild-type and $R B C S$-sense rice plants on $10 \mathrm{DAH}$ in the early, and $49 \mathrm{DAH}$ in the late-ripening stages were selected from each $15 \mathrm{~g} \mathrm{~N} \mathrm{~m}^{-2}$ plot. The stem or panicle number per unit land area calculated from the four sampled hills were indicated in Supplementary File 2: Table S1. The dry weights of the leaf blades, known as the photosynthetic assimilatory organs, were $180 \%$ higher ( $t$-test; $p=0.004)$ in the uppermost layer $(100-120 \mathrm{~cm})$ in $R B C S$ sense plants than in the wild-type rice plants at the early ripening stage, although there were no differences of those in $20-100 \mathrm{~cm}$ layer between the two genotypes ( $t$-test; $p$ > 0.05 , respectively) (Figs. 3A, B). The dry weights of leaf blades in the bottom layer $(0-20 \mathrm{~cm})$, where senescent leaf blades were likely to die, were lower ( $t$-test; $p=0.006)$ in RBCS-sense plants than in wildtype rice plants (Figs. 3A, B). The total dry weights of leaf blades in wild-type and $R B C S$-sense rice plants were not different ( $t$-test; $p=0.876)$ (Supplementary File 1: Figure S1), and significant differences were observed only if stratified cutting were detected (Figs. 3A, B). The relative light intensity in the second layer from the top ( $80-100 \mathrm{~cm}$ ) of the RBCS-sense plants was $17 \%$ lower $(t$-test; $p=0.007)$ than that of wild-type rice plants at the early ripening stage because the dry weights of leaf blades in the uppermost layer were larger (Figs. 3A, B). However, from the results of relationships between relative light intensity and cumulative leaf area index (LAl) of wild-type and RBCS-sense rice plants, there were no differences (Spearman rank correlation, $p=0.000$ in wild-type and RBCS-sense rice plants, respectively; covariance analysis, $\mathrm{K}$ : slope $p=0.973$, y-axis intercept $p=0.364$ ) in the light extinction between canopies of the two genotypes (Fig. 4). These results were obtained due to the low ratio of the dry weights of leaf blades in the uppermost layer relative to those of total leaf blades, about $1.8 \%$ in the wild-type and about $5.4 \%$ in $R B C S$ sense rice plants. In contrast, total dry weights of leaf blades of RBCS-sense plants were $16 \%$ higher ( $t$-test; $p=0.011$ ) than those of wild-type rice plants at the late ripening stage (Additional file 2: Fig. S1), although there were no significant differences (t-test; $p>0.05$, respectively) in dry weights of leaf blades at the same stage through the stratified distribution (Figs. 1C, D).

In the non-assimilatory organs, the stratified distribution of the dry weights of leaf sheaths and stems in the $80-100 \mathrm{~cm}$ and $20-80 \mathrm{~cm}$ layers was higher ( $t$-test; $p=0.013$ in $80-100 \mathrm{~cm}$ layer at early, and $p=$ 0.048 in $60-80 \mathrm{~cm}, p=0.011$ in $40-60 \mathrm{~cm}, p=0.002$ in $20-40 \mathrm{~cm}$ layers at the late ripening stages), in $R B C S$ sense plants than in wild-type rice plants at early (Figs. 3A, B) and late ripening stages (Figs. 3C, D), respectively. Total dry weights of the leaf sheaths and stems were greater in the RBCS-sense plants at the 
late ripening stage (t-test; $p=0.009$ ) than wild-type rice plants (Supplementary File 1: Fig. S1), although those were not different at the early ripening stage ( $t$-test; $p=0.334)$ (Supplementary File 1: Fig. S1). In the panicles, there were no significant differences in dry weights in the individual layer between two genotypes at both stages ( $t$-test; $p>0.05$, respectively) (Fig. 3 ). Total dry weights of the panicles of $R B C S$ sense plants were $5 \%$ higher ( $t$-test; $p=0.011$ ) than those of wild-type rice plants (Supplementary File 1 : Fig. S1), supporting the results of the increased brown rice yields in RBCS-sense plants compared to wildtype rice plants (Table 1). The dry weights of dead organs between the two genotypes were not different from each other ( $t$-test; $p>0.05$, respectively) at the early and late ripening stages, and were very low compared with the total dry weight production (Fig. 3, Supplementary File 1: Fig. S1).

\section{Enlarged leaf area of the flag leaves in RBCS-sense rice plants grown under sufficient $\mathrm{N}$ fertilization}

The plant height was slightly higher (t-test; $p=0.026)$ in RBCS-sense plants than in wild-type rice plants (Table 2). The area and the length of flag leaves were about $9 \%$ and $13 \%$ larger ( $t$-test; $p=0.028$ and $p=$ 0.001 , respectively) in $R B C S$-sense plants than in wild-type rice plants, respectively (Table 2 ). In contrast, there were no significant differences in the area and length of penultimate leaves, the height of the lamina joints of flag leaves and penultimate leaves, between two genotypes ( $t$-test; $p>0.05$, respectively) (Table 2). Thus, the higher plant heights of RBCS-sense rice plants were mainly due to the enlarged length of the flag leaves. Additionally, the flag leaves of $R B C S$ sense rice plants exclusively occupied in the uppermost layer (100-120 cm), since the penultimate leaves of two genotypes did not attain the uppermost layer because of the relationship between the lengths of penultimate leaves and the heights of their lamina joints (Fig. 1, Table 2).

\section{Preferential N partitioning to the flag leaves in the RBCSsense rice plants}

There were no differences ( $t$-test; $p=0.556$ ) in the total $\mathrm{N}$ contents of above-ground sections between two genotypes on $10 \mathrm{DAH}$ in the early ripening stage, although those of RBCS-sense plants were higher ( $t$-test; $p=0.001$ ) than those of wild-type rice plants on $49 \mathrm{DAH}$ in the late ripening stage (Supplementary File 3: Fig. S2). However, the stratified cutting analyses showed differences in organ-specific $\mathrm{N}$ contents along the vertical axis between the two genotypes. Fig. 5 indicates the vertical distribution of $\mathrm{N}$ in the canopies of wild-type and RBCS-sense rice plants at the early (Figs. 5A, B) and late ripening stages (Figs. 5C, D), respectively. The $\mathrm{N}$ contents of the leaf blades were $188 \%$ higher ( $t$-test; $p=0.008)$ in the uppermost layer $(100-120 \mathrm{~cm})$ where the flag leaves were found in RBCS-sense plants than in wild-type rice plants at the early ripening stage (Figs. 5A, B). In contrast, in the lower layer, $60-80 \mathrm{~cm}$ and $0-20 \mathrm{~cm}$, where the senescent leaf blades were present, $N$ contents of leaf blades were $25 \%$ and $57 \%$ lower $(t$-test; $p=0.012$ and $p=0.026$, respectively) in $R B C S$ sense plants than wild-type rice plants, respectively, at the same stage (Figs. 5A, B). In the non-assimilatory organs, the $\mathrm{N}$ contents of the leaf sheaths and stems of RBCS sense plants were higher ( $t$-test; $p=0.027$ ) than in wild-type rice plants in the layer of $80-100 \mathrm{~cm}$ at the early ripening stage, although there were no differences ( $t$-test; $p>0.05$, respectively) in those panicles between two genotypes (Figs. 5A, B). In contrast, the total $\mathrm{N}$ contents of each organ in the wild-type and 
$R B C S$ sense rice plants were not different (t-test; $p>0.05$, respectively) at the early ripening stage (Supplementary File 3: Fig. S2A).

In the late ripening stages, the total $\mathrm{N}$ contents of leaf blades, leaf sheaths and stems, and panicles in RBCS-sense rice plants were higher ( $t$-test; $p=0.019$ at leaf blades, $p=0.001$ at leaf sheaths and stems, and $p=0.011$ at panicles) than the wild-type rice plants at the late ripening stage (Supplementary File 3 : Fig. S2B). The stratified distribution of the $\mathrm{N}$ contents of leaf sheaths and stems in $0-40 \mathrm{~cm}$ layers were higher ( $t$-test; $p=0.019$ in $0-20 \mathrm{~cm}$ and $p=0.022$ in 20-40 cm layers) in RBCS-sense plants than wildtype rice plants, although there were no differences ( $t$-test; $p>0.05$, respectively) in $\mathrm{N}$ contents of leaf blades and panicles at the late ripening stage (Figs. 5C, D).

\section{Extended lifespan of flag leaves in RBCSsense rice plants}

The $\mathrm{CO}_{2}$ assimilation rate declines relating to the decrease of total $\mathrm{N}$, Rubisco, and Chl contents in leaves during leaf aging (Makino et al. 1985). Thus, the $\mathrm{CO}_{2}$ assimilation rate decline process and a decrease in LAl can be defined as leaf senescence. All the leaves of rice plants are senescent during the ripening period. The extended lifespan of leaves has a considerable effect on the yield of rice plants. In the current research, there were no significant differences in the LAl between two genotypes at the early ripening stage, but the LAI was $26 \%$ higher ( $t$-test; $p=0.003$ ) in RBCS-sense plants than in wild-type rice plants at the late ripening stage (Fig. 6). These results indicated that the reduction rate in the LAl of the RBCS sense plants during the ripening period is lower than that of the wild-type rice plants. Additionally, the Rubisco, total $\mathrm{N}$, and $\mathrm{Chl}$ in the flag leaves of the RBCS-sense plants exhibited higher than those in wildtype rice plants throughout the ripening period (Figs. 2B-D). These results indicate that the photosynthetic capacity was kept at higher levels in the RBCS-sense plants than in wild-type rice plants throughout the ripening period.

\section{High accumulation of starch in the leaf sheaths and stems of RBCSsense rice plants at the late ripening stage}

To evaluate the photosynthetic capacity of the rice plants during the ripening periods, it is important to measure the amounts of photosynthates accumulated in the sheaths and stems at the harvest stage. When the nonstructural carbohydrates (NSC) contents in the sheathe and stems used for stratified cutting were measured, that of RBCS-sense plants in the 20-40 cm layer were about $29 \%$ higher ( $t$-test; $p=0.019$ ) than wild-type rice plants (Fig. 7A). Looking at the components of NSC, the starch contents of the sheaths and stems in RBCSsense plants in 20-60 cm layers were significantly about $107 \%$ higher ( $t$-test; $p=$ 0.020 in $20-40 \mathrm{~cm}$ and $p=0.040$ in $40-60 \mathrm{~cm}$ in layers) than in wild-type rice plants (Fig. 7B). In contrast, there were no clear differences ( $t$-test; $p>0.05$, respectively) in the contents of sucrose and glucose in each layer (Figs. 7C, D).

\section{Discussion}


Over the past decade, many crops with enhanced photosynthetic capacity have been developed to improve in yields (Bailey-Serres et al. 2019). However, at the field level, there were no convincing examples of increased yields due to photosynthesis improvement until 2019 (Sinclair et al. 2019). For this reason, there had been skepticism about whether the improvement of photosynthetic capacity could increase crop yields (Sinclair et al. 2019). Long (2020) evaluated our previous research (Yoon et al. 2020) using in the paddy field about $R B C S$-sense rice plants as having provided the clearest evidence that this skepticism may be misplaced. Here, it was concluded that important factors of the increased grain yields of the RBCS-sense rice plants had been improvements of the photosynthetic capacity by physiological and architectural changes in the flag leaves, in addition to higher leaf $\mathrm{N}$ and Rubisco contents throughout the ripening periods.

\section{Flag leaves largely contribute to the increased yield of the RBCS-sense rice plants}

During the ripening periods, the RBCS-sense rice plants exhibited increased $\mathrm{N}$ absorption, and high levels of Rubisco protein in the flag leaves were maintained throughout the ripening period (Yoon et al. 2020). In addition to the relationship between the two phenomena, other factors that should have been clarified relating to the increased yields of the RBCS-sense rice plants, such as the effect of the light-reception postures in the canopies and of the leaves below the flag leaves existing in the ripening stage on the yields had remained unsolved. Our current results clearly showed that $\mathrm{N}$ was preferentially distributed to the flag leaves of the RBCS-sense rice plants at the early ripening stage (Fig. 2C, Figs. 5A, B). The greater $\mathrm{N}$ distributions to the flag leaves contribute to more increase in Rubisco content with enhancing the photosynthetic capacity in the flag leaves under sufficient $N$ fertilization (Fig. 1, 2). Additionally, the flag leaves of the RBCS-sense plants had an enlarged leaf area compared to wild-type plants, although the leaf area did not vary in the lower leaves (Table 2). While the enlarged flag leaves of the RBCS-sense occupied larger spatial areas of the uppermost layers in the canopies at the early ripening stage compared to wild-type rice plants (Figs. 3A, B), it did not substantially prevent the penetration of light into the lower leaves. (Fig. 4). Thus, the light-receptions in the canopies of wild-type and RBCS-sense rice plants are not different. The photosynthetic activity of the penultimate leaves between two genotypes was almost the same level at the early ripening stage (Fig. 1B). For these reasons, the contribution of leaves besides the flag leaves to yields during the ripening stage is different from the wild-type and $R B C S$ sense rice plants.

The flag leaf in rice plants is the last leaf to appear that expands fully about 10 days before heading (Hoshikawa 1981, Mae and Ohira 1981). In rice plants, photosynthesis in the flag leaves is the greatest contributor to ripening (Hoshikawa 1983, Yoshida 1981, Cook et al. 1983). Many physiological and molecular biological research indicated that flag leaves have the highest photosynthetic activity in the crop canopy after heading, which would be closely correlated with grain yield (Adachi et al. 2017 and 2019, Gu et al. 2012, Takai et al. 2013, Carmo-Silva et al. 2017, Honda et al. 2021). Thus, it was concluded that the increases in the yields of the RBCS-sense plants compared to the wild-type rice plants are largely due to the functions of their enlarged flag leaves with high photosynthetic capacity in the uppermost layers of the canopies. 


\section{Low $\mathrm{CO}_{2}$ conditions may promote increasing Rubisco production efficiency}

Our previous research using artificial growth chambers showed that $R B C S$-sense rice plants are further promoted at low $\mathrm{CO}_{2}$ concentration and may be mediated by increasing the total leaf $\mathrm{N}$ content with increasing $\mathrm{N}$ uptake (Sudo et al. 2014). This study observed a $\mathrm{CO}_{2}$ depletion of up to $70 \mu \mathrm{mol} \mathrm{mol}{ }^{-1}$ from atmospheric levels in the $15 \mathrm{~g} \mathrm{~N} \mathrm{~m}^{-2}$ plots, compared to the $0 \mathrm{~g} \mathrm{~N} \mathrm{~m}^{-2}$ plots $\mathrm{N}$ throughout the ripening period (Fig. 2A). This $\mathrm{CO}_{2}$ depletion may have resulted from excess plant growth of the RBCS-sense rice plants under higher $\mathrm{N}$ application. In rice plants, the total leaf $\mathrm{N}$ and Rubisco contents are highly correlated with each other, and additionally, the ratio of Rubisco to leaf $\mathrm{N}$ content increases with increasing leaf $\mathrm{N}$ content (Makino et al. 1994). Thus, the lower $\mathrm{CO}_{2}$ concentrations may also promote increased $\mathrm{N}$ absorption and increasing Rubisco production contributed to the improvement of photosynthesis in RBCS-sense rice plants in the canopy.

\section{$\mathrm{N}$ promotes to increase Rubisco overproduction effects and gives an extended lifespan of the flag leaves}

The greater $\mathrm{N}$ distribution to the flag leaves of the RBCS-sense rice plants gives two additional effects: 1) promotion of Rubisco overproduction effects, 2) extending lifespan of the flag leaves. Rubisco increases in amounts and production efficiency as $\mathrm{N}$ increases the leaf blades (Makino et al. 1994). Therefore, the overproduction of Rubisco in the flag leaves of RBCS-sense rice plants due to greater $\mathrm{N}$ distribution to the flag leaves may have led to higher photosynthetic capacity. To increase yields in rice, it is essential to enhance the $\mathrm{CO}_{2}$ assimilation rates and to maintain higher photosynthesis throughout the ripening period. Our results indicated that the LAI duration of RBCS-sense rice plants was longer than in wild-type plants (Fig. 7), and Rubisco, total $\mathrm{N}$, and Chl contents in the flag leaves kept higher in RBCS-sense plants until the late ripening period (Figs. $2 \mathrm{~B}-\mathrm{D}$ ). In fact, the $\mathrm{CO}_{2}$ concentrations in the canopies of $R B C S$-sense rice plants in the $15 \mathrm{~g} \mathrm{~N} \mathrm{~m}^{-2}$ plots were lower than those in the $0 \mathrm{~g} \mathrm{~N} \mathrm{~m}^{-2}$ plot from reproductive until later ripening periods (Fig. 2A). This means that RBCS-sense plants have a long-term high photosynthetic capacity to manufacture greater photosynthates throughout the ripening period.

\section{Greater source capacity as high photosynthetic activity in the RBCS-sense rice plants}

RBCS-sense rice plants showed about 2-fold increased starch accumulation in the leaf sheaths and stem in lower layers than wild-type rice plants (Fig. 7B). In rice plants, photosynthates accumulate in spikelets mostly during the early and middle periods of ripening (Yoshida 1981). In the later ripening period, excess photosynthates that are no longer stored in the spikelets are accumulated in the leaf sheaths and stems (Cock and Yoshida 1972, Nagata et al. 2002). As indicated in Table1, the ratio of filled spikelets in the RBCS-sense rice plants in the $15 \mathrm{~g} \mathrm{~N} \mathrm{~m}^{-2}$ plots was $88.9 \%$, close to the upper limit of the ratio, while that in the wild-type rice plants was $83.8 \%$, which still had some space to accumulate dry matter in their spikelets. Differences in the ratio of filled spikelets and the amount of starch accumulated in the leaf sheath and stem between two genotypes could mainly be attributed to the difference in their photosynthetic abilities of flag leaves during the ripening period. These facts indicated that the RBCS sense rice plant has greater source capacity and high photosynthesis than its sink size. In our previous 
research, high-yielding japonica rice cultivars with large-grain; Akita 63 exhibited high grain yields but a lower ratio of filled spikelets under sufficient $\mathrm{N}$ fertilization in paddy fields (Mae et al. 2006, Makino et al. 2020). The phenomenon seems to be due to the limited photosynthetic capacity relative to its sink size caused by its spikelet size of Akita 63. If rice plants with large sink sizes such as Akita 63 are crossed with the RBCS-sense rice plants with greater source capacity, further increases in grain yields can be expected.

\section{Conclusion}

In our previous research, transgenic rice plants overproducing Rubisco (RBCS-sense rice plants) showed increased grain yields cultivated in an experimental paddy field with sufficient $\mathrm{N}$ fertilization (Yoon et al. 2020). It was speculated that the increased yields of the RBCS-sense rice plants were due to an increase in $\mathrm{N}$ absorption and the maintenance of higher Rubisco contents in their flag leaves over a long duration. This research clearly showed that RBCS-sense rice plants have the enlarged flag leaves with high photosynthetic capacity by higher Rubisco contents and with long-term of lifespan throughout the ripening period. The flag leaves greatly contributed to the increased yields of the RBCS-sense rice plants. The greater $\mathrm{N}$ distributions to the flag leave led to an increase in Rubisco contents and leaf area as well as the lifespan extension of the flag leaves in the RBCS-sense rice plants.

\section{Methods}

\section{Plant material and field growth conditions}

Rice (Oryza sativa L. cv. Notohikari) was transformed with OsRBCS2 (gene identifier Os12g0274700 in The Rice Annotation Project Database; https://rapdb.dna.affrc.go.jp/) cDNA in the sense orientation under the control of its own OSRBCS2 promoter, and transgenic lines with a substantially increased Rubisco content were selected (RBCS-sense rice plants, line name; Sr-26-8) (Suzuki et al. 2007). T3 progenies of the line Sr-26-8 was backcrossed to non-transformed (wild-type) rice plants (Oryza sativa L. $\mathrm{cv}$. Notohikari) twice (BC1 and BC2), and BC2F1 seeds were obtained by selfing BC2. From BC2F2 seeds obtained by selfing BC2F1, plants with homozygous for the OsRBCS2 transgene were selected. In the present research, BC2F6 progeny of the line Sr-26-8 expressing about $130 \%$ of the Rubisco of wild-type plants were used. The wild-type rice plants were used as controls.

Rice plants of two genotypes were grown in the Isolated Farm for Genetically Modified Plants (Isolated Paddy Field) (Hossain et al. 2000, Yoon et al. 2020) of the Field Science Center, Tohoku University (Kawatabi Field Center; $38^{\circ} 44^{\prime} \mathrm{N}, 140^{\circ} 45^{\prime} \mathrm{E}$, at $140 \mathrm{~m}$ altitude) in 2021 . The soil in the isolated paddy field (Furukawa sandy alluvial soil) was sandy, had pH5.8, $12.0 \mathrm{~g}$ total $\mathrm{C} \mathrm{kg}^{-1}, 1.0 \mathrm{~g}$ total $\mathrm{kg}^{-1}$ and $10.0 \mathrm{cmol}$ $(+) \mathrm{kg}^{-1}$ cation exchange capacity (Yoon et al. 2000). Seedling were grown in an isolated greenhouse from $18^{\text {th }}$ April in 2021. Seedling were planted in the paddy field at a hill spacing of $0.300 \times 0.163 \mathrm{~m}(20.5$ hills $\mathrm{m}^{-2}$ ) with three seedlings per hill. Plants were grown with the amounts of $0 \mathrm{~g}, 8 \mathrm{~g}$, and $15 \mathrm{~g} \mathrm{~N} \mathrm{~m}^{-2}$ fertilization, along with ammonium sulfate of $4 \mathrm{~g} \mathrm{~N} \mathrm{~m}^{-2}$ at $8 \mathrm{~g} \mathrm{~N} \mathrm{~m}^{-2}$ and $15 \mathrm{~g} \mathrm{~N} \mathrm{~m}^{-2}$ plots and controlled- 
release fertilizers (LP70-type polyolefin-coated urea, JCAM AGRO Co.) of $4 \mathrm{~g} \mathrm{~N} \mathrm{~m}^{-2}$ and $7 \mathrm{~g} \mathrm{~N} \mathrm{~m}^{-2}$ at $8 \mathrm{~g} \mathrm{~N}$ $\mathrm{m}^{-2}$ and $15 \mathrm{~g} \mathrm{~N} \mathrm{~m}^{-2}$ plots, respectively, for basal application. As a top-dressing fertilizer, $2 \mathrm{~g} \mathrm{~N} \mathrm{~m}^{-2}$ of ammonium sulfate was applied twice to both plots during reproductive stage. LP-70 type fertilizers linearly release $80 \%$ of their total $\mathrm{N}$ contents for 70 days at $20-30^{\circ} \mathrm{C}$. $\mathrm{N}$ fertilizer did not supply to $0 \mathrm{~g} \mathrm{~N} \mathrm{~m}^{-}$ 2 plots. Calcium superphosphate ( $4.37 \mathrm{~g}$ Phosphate $\mathrm{m}^{-2}$ ) and potassium chloride $\left(6.63 \mathrm{~g}\right.$ Potassium m$\left.{ }^{-2}\right)$ were applied to all plots on $3^{\text {rd }}$ to $5^{\text {th }}$ day before transplantation. The weeds, insects and diseases were controlled as required to avoid yield loss. The full-heading date was defined as the time when $40 \%$ of the panicles had emerged. Heading dates was $1^{\text {st }}$ August in 2021. Two genotypes of rice plants were considered to have reached yellow, and the plants were harvested in $0 \mathrm{~g}$ and $15 \mathrm{~g} \mathrm{~N} \mathrm{~m}^{-2}$ plots on $20^{\text {th }}$ September and $8 \mathrm{~g} \mathrm{~N} \mathrm{~m}^{-2}$ plots on $29^{\text {th }}$ September in 2021. During this experimental period, the climate conditions at Kawatabi Field Center is shown in Supplementary File 3: Table S2.

\section{Measurement of relative light intensity in canopy, dry weight, and leaf area}

Characteristics in rice canopy were investigated at two growth stages: in early and in late ripening stages. The relative light intensity within the canopy at every $20 \mathrm{~cm}$ interval from the soil surface to the top of the canopy was measured with photometer (Light Meter Model LI-250, Li-Cor, Lincoln, NE, USA) at early ripening stage ( $11^{\text {th }}$ August in 2021). Three sets of samples consisted of four neighboring hills with an average number of panicles for the wild-type and $R B C S$ sense rice plants at $10 \mathrm{DAH}$ in the early ripening ( $11^{\text {th }}$ August in 2021) and 49 DAH in the late ripening stages ( $19^{\text {th }}$ September in 2021), respectively, were selected from each plot applied with $15 \mathrm{~g} \mathrm{~N} \mathrm{~m}^{-2}$ fertilization. The relative light intensity was measured at 5 points between the plants in each layer. Plants were then clipped every $20 \mathrm{~cm}$ vertically and separated into leaf blades, leaf sheaths and stems, and panicles. Leaf area was measured with a leaf area meter (AMM-8; Hayashi-denko, Tokyo, Japan).

The samples which were measured relative light intensity were then dried in a ventilated oven at $80^{\circ} \mathrm{C}$ for 3 days to a constant dry weight. We calculated the specific leaf area of this sample as the leaf area divided by the dry weight and calculated the leaf areas by multiplying the specific leaf area by the dry weight of leaves (San-oh et al. 2004).

\section{Measurements of $\mathrm{CO}_{2}$ assimilation rate of leaves and atmosphere $\mathrm{CO}_{2}$ concentrations in the canopies}

The rates of $\mathrm{CO}_{2}$ assimilation of flag and the penultimate leaves were measured using portable gas exchange system (LI-6400XT, Li-Cor) at early ripening stage. The measurement of flag leaves was done on one DHA in the early ripening stage and that of penultimate leaves were done on four DHA. Measurements were made at a photosynthetic photon flux density of 1500, 100, 500 and $100 \mu \mathrm{mol}$ quanta $\mathrm{m}^{-2} \mathrm{~s}^{-1}$, at a leaf temperature of $28-32^{\circ} \mathrm{C}$, and $400 \mu \mathrm{mol} \mathrm{mol}^{-1}$ of $\mathrm{CO}_{2}$ concentration in the leaf chamber of $\mathrm{LI}-6400 \mathrm{XT}$. The $\mathrm{CO}_{2}$ concentration in the vicinity adjacent to the flag leaf (top leaf) of $R B C S$ sense plants in the $0 \mathrm{~g}$ and $15 \mathrm{~g} \mathrm{~N} \mathrm{~m}^{-2}$ plots was continuously monitored with an IRGA (Horiba ASSA1110 , Horiba, Kyoto, Japan) from -26 to 35 DAH as reproductive and ripening periods. 


\section{Physiological and biochemical analysis}

Dried materials were milled to fine powdered, and then the plant $\mathrm{N}$ content was determined using Nessler's reagent after Kjeldahl digestion. Starch, sucrose and glucose contents in these dried materials were determined by the measurements of using an F-kit (J.K. International, Tokyo, Japan) according to our previous experiment (Sudo et al. 2014). For Rubisco quantification, we sampled flag and penultimate leaves from the hills different from the hills that were used for stratified cutting in the plots applied with $15 \mathrm{~g} \mathrm{~N} \mathrm{~m}^{-2}$ fertilization at 3 stages: early ripening (for flag leaves on $5^{\text {th }}$ August in 2021, for penultimate leaves on $9^{\text {th }}$ August in 2021) middle ripening (for flag leaves on $27^{\text {th }}$ August 2021, for penultimate leaves on $31^{\text {st }}$ August in 2021) and late ripening stage (for flag leaves on $19^{\text {th }}$ September in 2021). The Rubisco content was determined spectrophotometrically by formamide extraction of the Coomassie Brilliant Blue R-250-stained subunit bands from the gel (Makino et al. 1994) using calibration curves made with bovine serum albumin (BSA).

\section{Rice yield measurement}

The numbers of filled and unfilled spikelets were measured with a counting machine for plant seeds (WAVER IC-VA, VAi, AIDEX Co.). The filled spikelets were separated by submerging the hand-threshed spikelets in a $\mathrm{NaCl}$ solution with a specific gravity of $1.06 \mathrm{~g} \mathrm{~cm}^{-3}$, and the ratio of filled spikelets was calculated by comparing the number of filled spikelets with the number of total spikelets. The filled spikelets were then hulled and oven-dried at $80^{\circ} \mathrm{C}$ to a constant weight for determining grain dry weight. The weight of the hulled (brown) rice was adjusted to a fresh weight with a moisture content of $0.15 \mathrm{~g}$ $\mathrm{H}_{2} \mathrm{O} \mathrm{g}^{-1}$. The brown rice yield was calculated by multiplying the grain number per unit land area, the ratio of filled grains and the brown rice weight per grain, which constitutes the 'yield component' (Yoon et al. 2020).

\section{Statistical analyses}

The data are expressed as the mean \pm standard error. Student's $t$-test was performed with Excel (Microsoft). Scatter diagrams and registration lines were created and calculated using Excel (Microsoft). Correlations were tested by Spearman's rank-order correlation coefficient ( $P$ value) and covariance analyses were conducted using Excel Tokei (BellCurve).

\section{Abbreviations}

Chl; chlorophyll; DAH; days after heading; LAl, leaf area index; N, nitrogen; NSC, nonstructural carbohydrates; RBCS, Rubisco small subunit, Rubisco, ribulose-1,5-bisphosphate carboxylase/oxygenase.

\section{Declarations}

\section{Acknowledgements}


We are grateful to Professor Mizuhiko Nishida, Mr. Kazumi Suzuki, and Mr. Toru Uno of Kwatabi Field Center, Graduate School of Agricultural Science, Tohoku University for their support for this experiment. We would like to thank Professor Mitsue Miyao, Associate Professor Toshihiko Hayakawa, and Assistant Professor Soichi Kojima of Graduate School of Agricultural Science, Tohoku University for critical advice on this experiment. We thank laboratory members; Ms. Rina Nagao, Mr. Ryotaro Kitayama, Ms. Shiori Sato, and Ms. Haruka Sugeno for their help in the field experiments reported in this research. This work was registered on 18 May 2016 at the Biosafety Clearing-House Management Centre, which is established under the Cartagena Protocol on Biosafety to the Convention on Biological Diversity (an international agreement on biosafety created as a supplement to the Convention on Biological Diversity effective since 2003).

\section{Funding}

This work was supported by KAKENHI Grant No. JP16H06379 (to Makino, A.) and International Research Fellow Grant No. 21F21086 (to Yoon, D-K.) from the Japan Society for the Promotion of Science.

\section{Availability of Data and Materials}

The datasets supporting the conclusions of this article are included within the article and its additional files.

\section{Authors' Contributions}

MT, MK and D-KY performed most of the experiments. MT designed this study. MT and KI wrote the manuscript. TM, HI and AM advised and assisted in the design of this study and in writing the manuscript. All authors read and approved the final manuscript.

\section{Ethics Approval and Consent to Participate}

Not applicable.

\section{Competing Interests}

The authors declare that they have no competing interests.

\section{Author details}

${ }^{1}$ Graduate School of Agricultural Science, Tohoku University, 468-1 Aramaki-Aoba, Aoba-ku, Sendai 9808572, Japan.

*Correspondence author, E-mail; keiki.ishiyama.e5@tohoku.ac.jp, FAX; +81-22-757-4290

\section{References}


Adachi S, Yoshikawa K, Yamanouchi U, Tanabata T, Sun J, Ookawa T, Yamamoto T, Sage RF, Hirasawa T, Yonemaru J. (2017). Fine mapping of carbon assimilation rate 8 , a quantitative trait locus for flag leaf nitrogen content, stomatal conductance and photosynthesis in rice. Frontiers in Plant Science 8: 60

Adachi S, Yamamoto T, Nakae T, Yamashita M, Uchida M, Karimata R, Ichihara N, Soda K, Ochiai T, Ao R, Otsuka C, Nakano R, Takai T, Ikka T, Kondo K, Ueda T, Ookawa T, Hirasawa T (2019) Genetic architecture of leaf photosynthesis in rice revealed by different types of reciprocal mapping populations. J Exp Bot 70: 5131-5144

Bailey-Serres J, Parker JE, Ainsworth EA, Oldroyd GED, Schroeder JI (2019) Genetic strategies for improving crop yields. Nature 575: 109-118

Carmo-Silva E, Andralojc PJ, Scales JC, Driever SM, Mead A, Lawson T, Raines CA, Parry MAJ (2017) Phenotyping of field-grown wheat in the UK highlights contribution of light response of photosynthesis and flag leaf longevity to grain yield. J Exp Bot 68: 3473-3486

Canfield DE, Glazer AN, Falkowski PG (2010) The evolution and future of Earth's nitrogen cycle. Science 330: $192-196$

Cook MG, Evans LT (1983) Some physiological aspects of the domestication and improvement of rice (Oryza spp). Field Crops Res 6: 219-238

Cock JH, Yoshida S (1972) Accumulation of 14C-labelled carbohydrate before flowering and its subsequent redistribution and respiration in the rice plant. Proc Crop Sci Soc Jpn 41: 226-234

Evans LT (1998) Feeding the Ten Billion. Plants and Population Growth (Cambridge University Press, Cambridge)

Good AG, Beatty PH (2011) Fertilizing nature: a tragedy of excess in the commons. PLoS Biol 9: e1001124

Gu J, Yin X, Struik PC, Stomph TJ, Wang H (2012) Using chromosome introgression lines to map quantitative trait loci for photosynthesis parameters in rice (Oryza sativa L.) leaves under drought and well-watered field conditions. J Exp Bot 63: 455-469

Honda S, Ohkubo S, San NS, Nakkasame A, Tomisawa K, Katsura K, Ookawa T, Nagano AJ, Adachi S (2021) Maintaining higher leaf photosynthesis after heading stage could promote biomass accumulation in rice. 11: 7579

Hoshikawa K (1989) The growing rice plant (Nosan Gyoson Bunka Kyokai)

Hossain MZ, Shibuya Z, Saigusa M (2000) No-tillage transplanting system of rice with controlled availability fertilizer in the nursery box. 1 . Growth characteristics and yield of rice in these representative paddy soil. Tohoku J Agric Res 50: 71-86 
Long SP (2012) Mechanisms of plant response to global atmospheric change. Plant Cell Environ 35: 1705-1706

Long SP (2020) Photosynthesis engineered to increase rice yield. Nature Food 1: 105

Nagata K, Fukuta Y, Shimizu H, Yagi T, Terao T. (2002) Quantitative trait loci for sink size and ripening traits in rice (Oryza sativa L.). Breed Sci 52: 259-273.

Long SP, Marshall-Colon A, Zhu XG (2015) Meeting the global food demand of the future by engineering crop photosynthesis and yield potential. Cell 161: 56-66

Mae T, Ohira, K (1981) The remobilization of nitrogen related to leaf growth and senescence in rice plants (Oryza sativa L.). Plant Cell Physiol 22: 1067-1074

Mae T, Inaba A, Kaneta Y, Masaki S, Sasaki M, Aizawa M, Okawa S, Hasegawa S, Makino (2006) A largegrain rice cultivar, Akita 63, exhibits high yields with high physiological $\mathrm{N}$-use efficiency. Field Crops Res 97: 227-237

Makino A (2011) Photosynthesis, grain yield, and nitrogen utilization in rice and wheat. Plant Physiol 155: $125-129$

Makino A (2021) Photosynthesis improvement for enhancing productivity in rice. Soil Sci Plant Nutr Doi; https://doi.org/10.1080/00380768.2021.1966290

Makino A, Kaneta Y, Obara M, Ishiyama K, Kanno K, Kondo E, Suzuki Y, Mae T (2020) High yielding ability of a large-grain rice cultivar, Akita 63. Sci Rep 10: 12231

Makino A, Mae T, Ohira K (1985) Photosynthesis and ribulose-1,5-bisphosphate carboxylase oxygenase in rice leaves from emergence through senescence - quantitative analysis by carboxylation oxygenation and regeneration of ribulose 1,5-bisphosphate. Planta 166: 414-420

Makino A, Nakano H, Mae T (1994) Responses of ribulose-1,5-bisphosphate carboxylase, cytochrome f, and sucrose synthesis enzymes in rice leaves to leaf nitrogen and their relationships to photosynthesis. Plant Physiol 105: 173-179

San-oh Y, Kondo M, Okawa T, Hirasawa T (2004) Comparison of dry matter production and associated characters between direct-sown and transplanted rice plants in a submerged paddy field and relationships to planting patterns. Field Crops Res 42:79-89

Sinclair TR, Rufty TW, Lewis RS (2019) Increasing photosynthesis: Unlikely solution for world food problem. Trends Plant Sci 24:1032-1039

Sudo E, Suzuki Y, Makino A (2014) Whole-plant growth and N utilization in transgenic rice plants with increased or decreased Rubisco content under different $\mathrm{CO}_{2}$ partial pressures. Plant Cell Physiol 55: 
Suzuki Y, Ohkubo M, Hatakeyama H, Ohashi K, Yoshizawa R, Kojima S, Hayakawa T, Yamaya T, Mae T, Makino A (2007) Increased Rubisco content in transgenic rice transformed with the 'Sense' rbcs Gene. Plant Cell Physiol 48: 626-637

Takai T, Adachi S, Taguchi-Shiobara F, Sanoh-Arai Y, Iwasawa N, Yoshinaga S, Hirose S, Taniguchi Y, Yamanouchi U, Wu J, Matsumoto T, Sugimoto K, Kondo K, Ikka T, Ando T, Kono I, Ito S, Shomura A, Ookawa T, Hirasawa T, Yano M, Kondo M, Yamamoto T (2013) A natural variant of NAL1, selected in highyield rice breeding programs, pleiotropically increases photosynthesis rate. Sci Rep 3: 2149

von Caemmerer S, Evans JR (2010) Enhancing C 3 photosynthesis. Plant Physiol 154: 589-592

Yoon D-K, Ishiyama K, Suganami M, Tazoe Y, Watanabe M, Imaruoka S, Ogura M, Ishida H, Suzuki Y, Obara M, Mae T, Makino A (2020) Transgenic rice overproducing Rubisco exhibits increased yields with improved nitrogen-use efficiency in an experimental paddy field. Nature Food 1: 134-139

Yoshida S (1981) Fundamentals of rice crop science (The International Rice Research Institute)

\section{Tables}

Table1 Comparisons of total dry matter, yield, and yield components in 2021

\begin{tabular}{|c|c|c|c|c|c|c|}
\hline $\begin{array}{c}N \\
\text { fertilization } \\
\left(\mathrm{g} \mathrm{N} \mathrm{m}^{-2}\right)\end{array}$ & Line & $\begin{array}{l}\text { Total dry } \\
\text { matter } \\
(\mathrm{m} \Pi[)\end{array}$ & $\begin{array}{c}\text { Brown rice } \\
\text { yield } \\
(\mathrm{g} \mathrm{m} \mathrm{m})\end{array}$ & 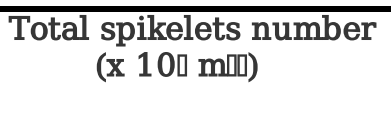 & $\begin{array}{l}\text { Single weight of } \\
\text { brown rice }(\mathrm{mg})\end{array}$ & $\begin{array}{l}\text { Ratio of filled } \\
\text { spikelets (\%) }\end{array}$ \\
\hline \multirow[t]{2}{*}{15} & Wild & $\begin{array}{l}1652 \pm 31 \\
(100)\end{array}$ & $\begin{array}{l}630 \pm 20 \\
(100)\end{array}$ & $29.2 \pm 0.8(100)$ & 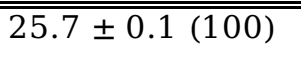 & $\begin{array}{l}83.8 \pm 1.0 \\
(100)\end{array}$ \\
\hline & $\begin{array}{l}R B C S- \\
\text { sense }\end{array}$ & $(109)^{*} \pm 42$ & $\begin{array}{c}733 \pm 20 \\
(116)^{*}\end{array}$ & $30.6 \pm 0.8(104)$ & $26.9 \pm 0.1(115)^{*}$ & $(106)^{*}$ \\
\hline \multirow[t]{2}{*}{8} & Wild & $\begin{array}{l}1369 \pm 48 \\
(100)\end{array}$ & $\begin{array}{l}541 \pm 19 \\
(100)\end{array}$ & $23.2 \pm 0.8(100)$ & $26.5 \pm 0.1(100)$ & $\begin{array}{l}88.0 \pm 1.8 \\
(100)\end{array}$ \\
\hline & $\begin{array}{l}R B C S- \\
\text { sense }\end{array}$ & $\begin{array}{l}1361 \pm 35 \\
(99)\end{array}$ & $\begin{array}{l}509 \pm 17 \\
(94)\end{array}$ & $21.8 \pm 0.5(93)$ & $26.5 \pm 0.3(100)$ & $\begin{array}{l}88.3 \pm 1.4 \\
(100)\end{array}$ \\
\hline \multirow[t]{2}{*}{0} & Wild & $\begin{array}{c}706 \pm \\
29(100)\end{array}$ & $\begin{array}{r}287 \pm 13 \\
(100)\end{array}$ & $11.7 \pm 0.4(100)$ & $27.6 \pm 0.2(100)$ & $\begin{array}{l}88.5 \pm 1.8 \\
(100)\end{array}$ \\
\hline & $\begin{array}{l}R B C S- \\
\text { sense }\end{array}$ & $\begin{array}{l}630 \pm \\
26(89)\end{array}$ & $\begin{array}{l}237 \\
(82)^{*}\end{array}$ & $10.0 \pm 0.4(85)^{*}$ & $26.2 \pm 0.2(94)^{*}$ & $\begin{array}{l}89.5 \pm 1.6 \\
(101)\end{array}$ \\
\hline
\end{tabular}

Mean values \pm the standard error of 15 independent plants is indicated. Statistical analysis was conducted using Student's $t$-test $(p<0.05)$. Asterisk denotes a statistically significant difference in the total dry matter production of the above-ground section, brown rice yield, total spikelet number per unit land area, single grain weight of brown rice, and the ratio of filled spikelets between the wild-type and $R B C S$-sense rice plants. Values in parentheses indicate the percentage of the value of the wild-type rice plants. The abbreviations stand as follows: "RBCS-sense"; transgenic rice plants overproducing Rubisco, "Wild"; wild-type rice plant.

Table 2 Parameters of the leaves in the early ripening stage under sufficient $\mathbf{N}$ fertilization. 


\begin{tabular}{|c|c|c|c|c|c|c|c|c|c|c|c|}
\hline \multirow[t]{2}{*}{ Line } & \multirow[t]{2}{*}{$\begin{array}{l}\text { Plant height } \\
\text { (cm) }\end{array}$} & \multicolumn{4}{|c|}{ Leaf area (cmI) } & \multicolumn{4}{|c|}{ Leaf length (cm) } & \multicolumn{2}{|c|}{$\begin{array}{l}\text { Height of the lamina joints } \\
\text { (cm) }\end{array}$} \\
\hline & & FL & & $\overline{P L}$ & & FL & & $\overline{\mathrm{PL}}$ & & FL & PL \\
\hline Wild & $\begin{array}{ll}115.8 \\
(100)\end{array}$ & $\begin{array}{l}31.4 \pm \\
(100)\end{array}$ & 0.9 & $\begin{array}{l}34.1 \pm \\
(100)\end{array}$ & & $\begin{array}{l}29.9 \quad \pm \\
(100)\end{array}$ & & $\begin{array}{l}36.2 \pm \\
(100)\end{array}$ & & $\begin{array}{c}88.4 \pm 1.1 \\
(100)\end{array}$ & $\begin{array}{c}61.0 \pm 1.1 \\
(100)\end{array}$ \\
\hline $\begin{array}{l}R B C S- \\
\text { sense }\end{array}$ & $\begin{array}{l}118.9 \pm 0.5 \\
(102)^{*}\end{array}$ & $\begin{array}{l}34.3 \pm \\
(109)^{*}\end{array}$ & 0.9 & $\begin{array}{l}35.9 \\
(105)\end{array} \pm$ & 0.9 & $\begin{array}{l}33.9 \pm \\
(113) *\end{array}$ & 0.9 & $\begin{array}{l}34.9 \pm \\
(96)\end{array}$ & 1.1 & $\begin{array}{l}88.2 \pm 4.7 \\
(99)\end{array}$ & $\begin{array}{l}61.9 \pm 0.9 \\
(101)\end{array}$ \\
\hline
\end{tabular}

Data represent means \pm the standard error (plant height: $\mathrm{n}=26$ in the wild-type and $\mathrm{n}=20$ in the $R B C S$-sense, leaf area of flag leaves: $\mathrm{n}=60$ in the wild-type and $R B C S$-sense, leaf area of the penultimate leaf blades: $\mathrm{n}=51$ in the wildtype and $\mathrm{n}=49$ in $R B C S$-sense, length of flag leaf: $\mathrm{n}=35$ in the wild-type and $\mathrm{n}=34$ in the $R B C S$-sense, leaf length of the penultimate leaf blades: $\mathrm{n}=20$ in the wild-type and $\mathrm{n}=23$ in the $R B C S$-sense, height of lamina joints: $\mathrm{n}=30$ in the wild-type and the $R B C S$-sense). ${ }^{*} p<0.05$ between the wild-type and $R B C S$-sense rice plants using Student's $t$-test. Values in parentheses indicate the percentage of the values of wild-type rice plants. The abbreviations stand as follows: "DAH"; days after heading, "FL"; flag leaves, "PL"; penultimate leaf blades, "RBCS-sense"; transgenic rice plants overproducing Rubisco, "Wild,"; wild-type rice plants.

\section{Figures}

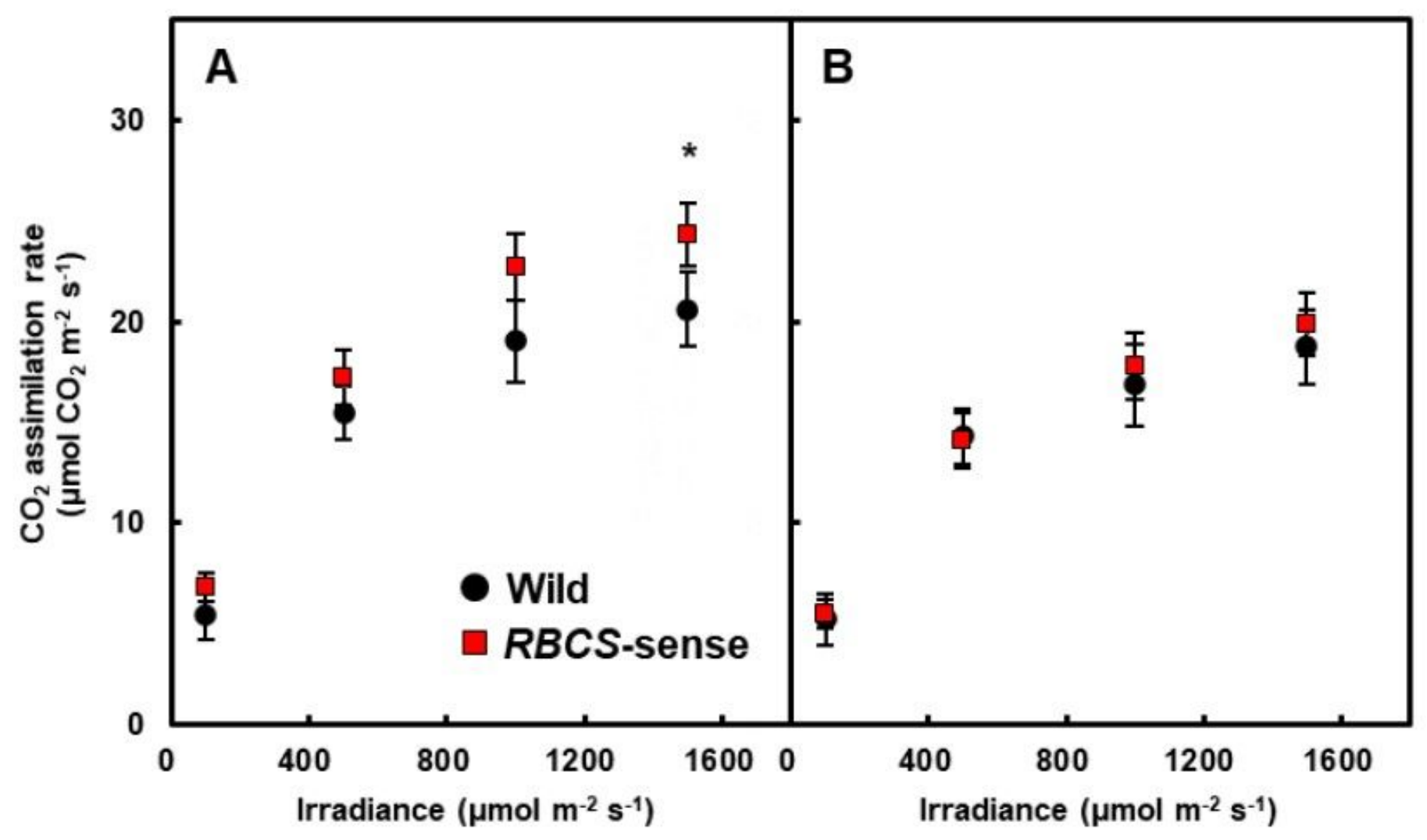

Figure 1

CO2 assimilation rate in the flag leaves $(A)$ and penultimate leaf blades $(B)$ of the wild-type and RBCSsense rice plants at the early ripening stage in the plots applied with $15 \mathrm{~g} \mathrm{~N} \mathrm{~m}-2$ fertilizer. The CO2 assimilation rates were measured on $1 \mathrm{DAH}$ for flag leaves and $4 \mathrm{DAH}$ for the penultimate leaves using 
$\mathrm{LI}-6400 \mathrm{XT}$ ( $\mathrm{Li}-\mathrm{Cor})$. Mean values \pm the standard error of $5-7$ independent rice plants is shown. The wildtype and RBCS-sense rice plants are represented by black circles and red squares, respectively. ${ }^{*} \mathrm{p}<0.05$ between the wild-type and RBCS-sense rice plants using Student's t-test. The abbreviations stand as following: "DAH"; days after heading, "RBCS-sense"; transgenic rice plants overproducing Rubisco, "Wild", wild-type rice plant.
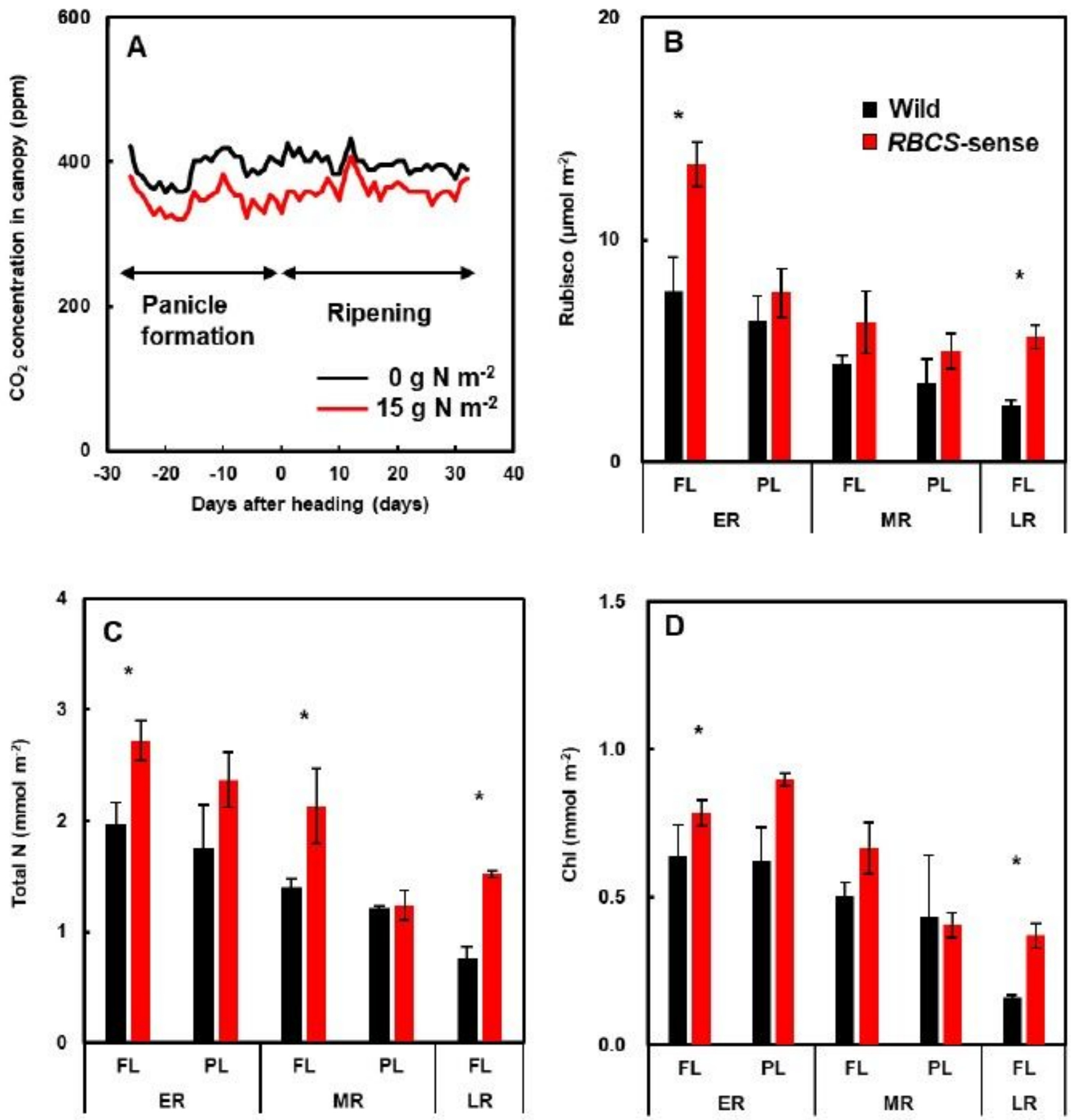

Figure 2

Changes in $\mathrm{CO} 2$ concentrations at airspace $10 \mathrm{~cm}$ below the top of the canopies of wild-type rice plants throughout reproductive and ripening periods in the plots applied with $15 \mathrm{~g}$ and $0 \mathrm{~g} \mathrm{~N} \mathrm{~m}-2$ fertilizer (A). 
Comparisons of Rubisco (B), total N (C), and Chl (D) contents per unit land area of flag leaves between wild-type and RBCS-sense rice plants at the early, middle, and late stages of ripening period in the plots applied with $15 \mathrm{~g} \mathrm{~N} \mathrm{~m}-2$ fertilizer. The $\mathrm{CO} 2$ concentrations in the canopies were measured throughout 26-36 DAH as reproductive and ripening periods (A). The flag and penultimate leaves of the wild-type and RBCS-sense rice plants for measuring Rubisco, total $\mathrm{N}$ and $\mathrm{Chl}$ contents were harvested from 4 to 8 DAH in early, from 26 to $30 \mathrm{DAH}$ in the middle, and $47 \mathrm{DAH}$ in the late ripening stages (B-D). The arrows represent the reproductive (panicle formation) and ripening periods, respectively. Mean values \pm the standard error of 3-5 independent of the flag leaves and penultimate leaf blades of wild-type and RBCSsense rice plants, respectively. ${ }^{\star} \mathrm{p}<0.05$ between the wild-type and RBCS-sense rice plants using Student's t-test. The abbreviations stand as follows: "Chl”; chlorophyll, "DAH"; days after heading, "ER"; early ripening stage, "FL"; flag leaves, "LR"; late ripening stage, "MR"; middle ripening stage, " $\mathrm{PL}$ "; penultimate leaf blade, "RBCS-sense"; transgenic rice plants overproducing Rubisco, "Wild"; wild-type rice plant. 

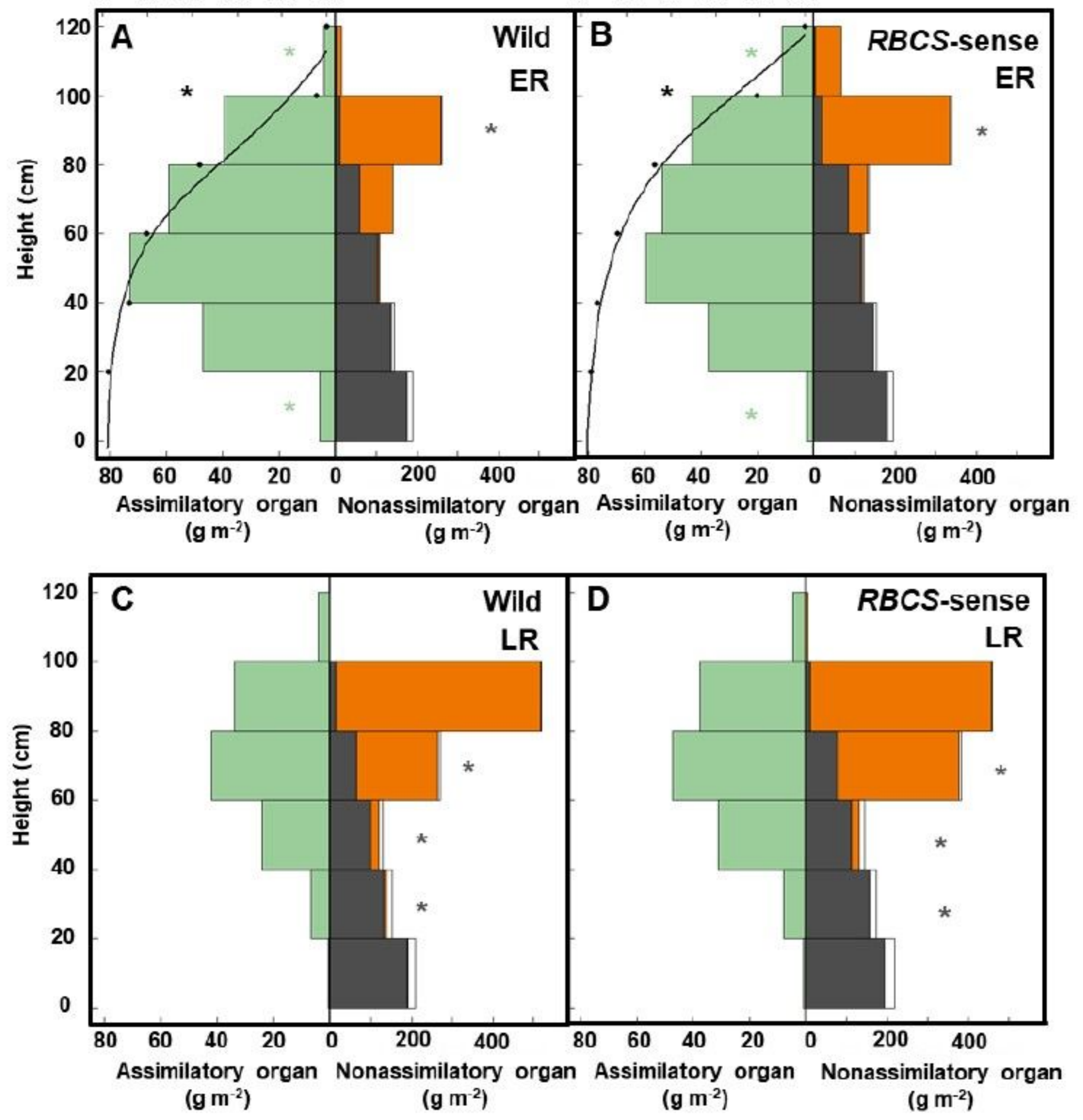

Figure 3

Changes in the wild-type ( $A$ and $C$ ) and RBCS-sense rice plants ( $B$ and $D$ ) canopy structures on 10 DAH in early and $49 \mathrm{DAH}$ in late ripening stages in the plots applied with $15 \mathrm{~g} \mathrm{~N} \mathrm{~m}-2$ fertilizer. Mean values \pm the standard error of three independent plots are indicated. ${ }^{*} p<0.05$ between the wild-type and RBCS-sense rice plants using Student's t-test. The dry weights of leaf blades, panicles, sheathes and stems, and dead organs are represented by green, orange, dark gray, and white bars, respectively. -0 indicates relative 
light intensity. The abbreviations stand as follows: "DAH”; days after heading, "ER"; early ripening stage, "LR"; late ripening stage, "RBCS-sense”; transgenic rice plants overproducing Rubisco, "Wild”; wild-type rice plants.

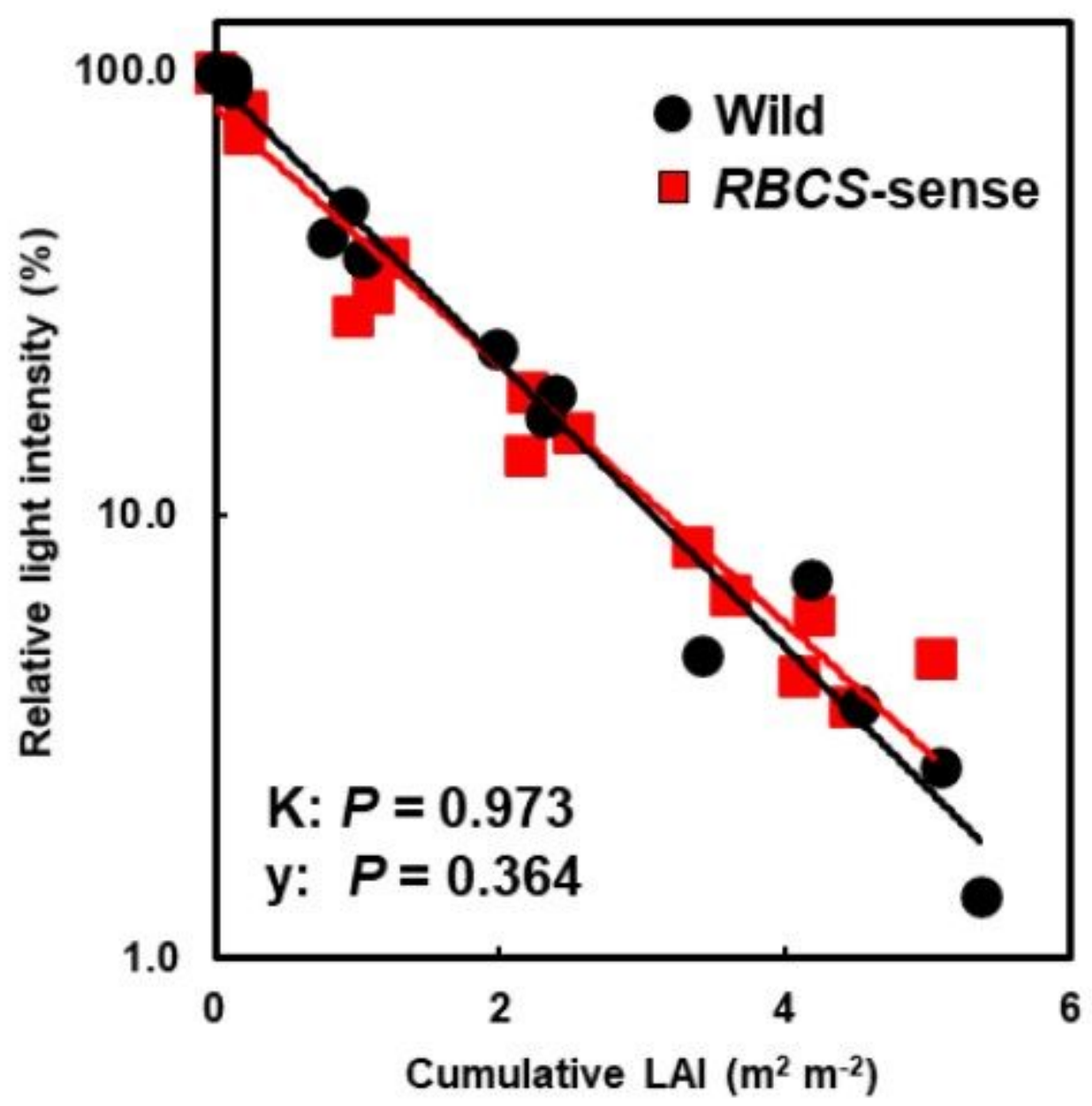

Figure 4

Relationships between relative light intensity and cumulative leaf area index (LAl) of the wild-type and RBCS-sense rice plants on 10 DAH in the early ripening stage in the plots applied with $15 \mathrm{~g} \mathrm{~N} \mathrm{~m}-2$ fertilizer. The wild-type and RBCS-sense rice plants are represented by black circles and red squares, respectively. The slope of the line represents the light extinction coefficient (K). Covariance analyses were conducted between wild-type and RBCS-sense rice plants, and no significant differences were detected in the light extinction coefficient $(K)$ and the intercept $(\mathrm{y})$. The abbreviations stand as follows: "LAl"; leaf area index, "RBCS-sense”; transgenic rice plants overproducing Rubisco, "Wild”; wild-type rice plants. 


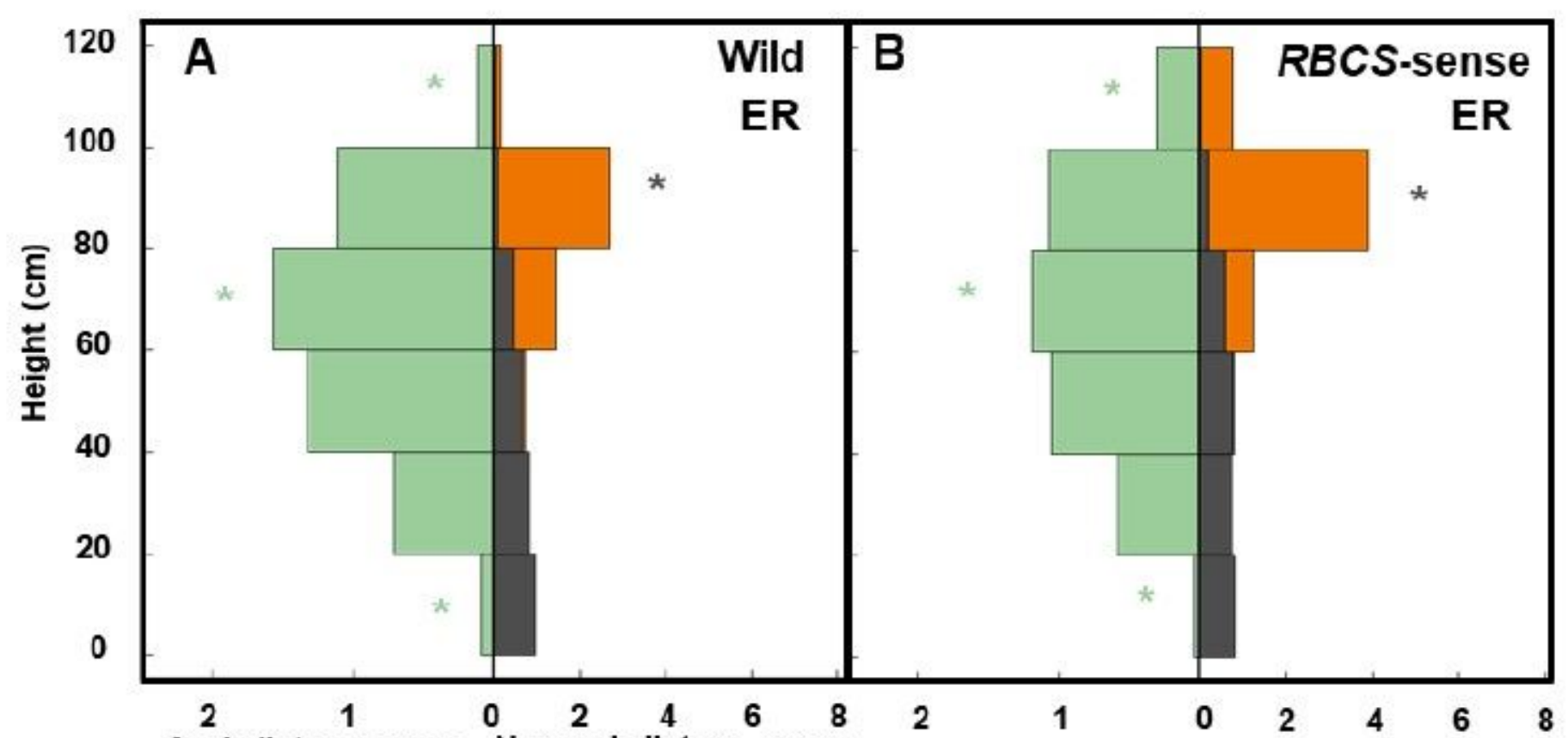

Assimilatory organ Nonassimilatory organ Assimilatory organ Nonassimilatory organ $\left(g^{-2}\right)$ $\left(g^{-2}\right)$ $\left(\mathrm{g} \mathrm{m}^{-2}\right)$ $\left(\mathrm{g} \mathrm{m}^{-2}\right)$

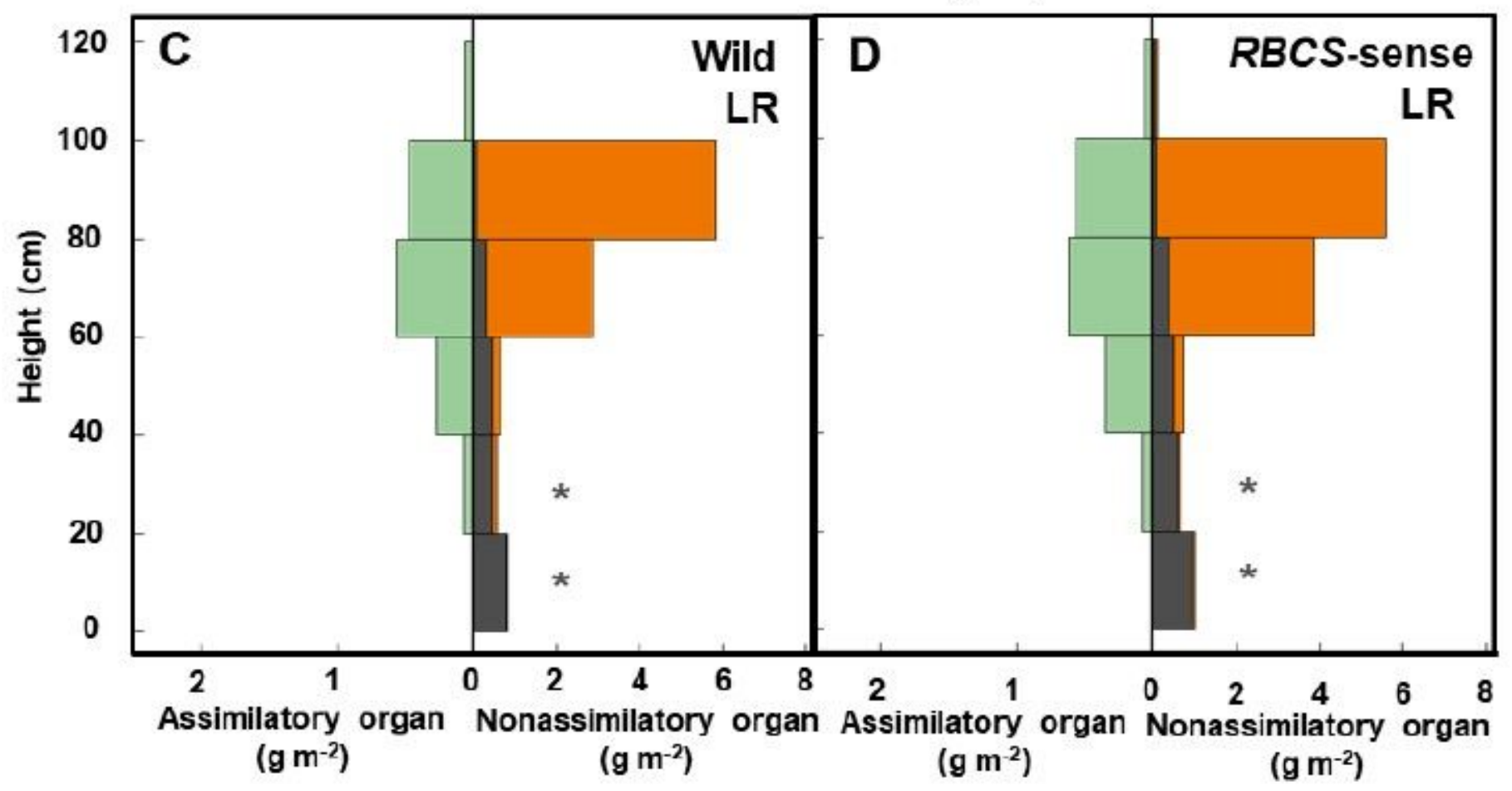

Figure 5

Changes in the vertical distribution of $\mathrm{N}$ content in the canopies of the wild-type ( $\mathrm{A}$ and $\mathrm{C}$ ) and RBCSsense rice plants (B and $D$ ) at $10 \mathrm{DAH}$ in early and $49 \mathrm{DAH}$ in late ripening stages in plots applied with 15 $\mathrm{g} \mathrm{N} \mathrm{m}-2$ fertilizer. Mean values \pm the standard error of three independent plots are indicated. ${ }^{*} \mathrm{p}<0.05$ between the wild-type and RBCS-sense rice plants using Student's t-test. The $\mathrm{N}$ content of leaf blades, panicles, and sheathes and stems are represented by green, orange, and dark gray bars, respectively. The 
abbreviations stand as following: "ER"; early ripening stage, "LR"; late ripening stage, "N"; nitrogen, "RBCSsense"; transgenic rice plants overproducing Rubisco, "Wild"; the wild-type rice plants.

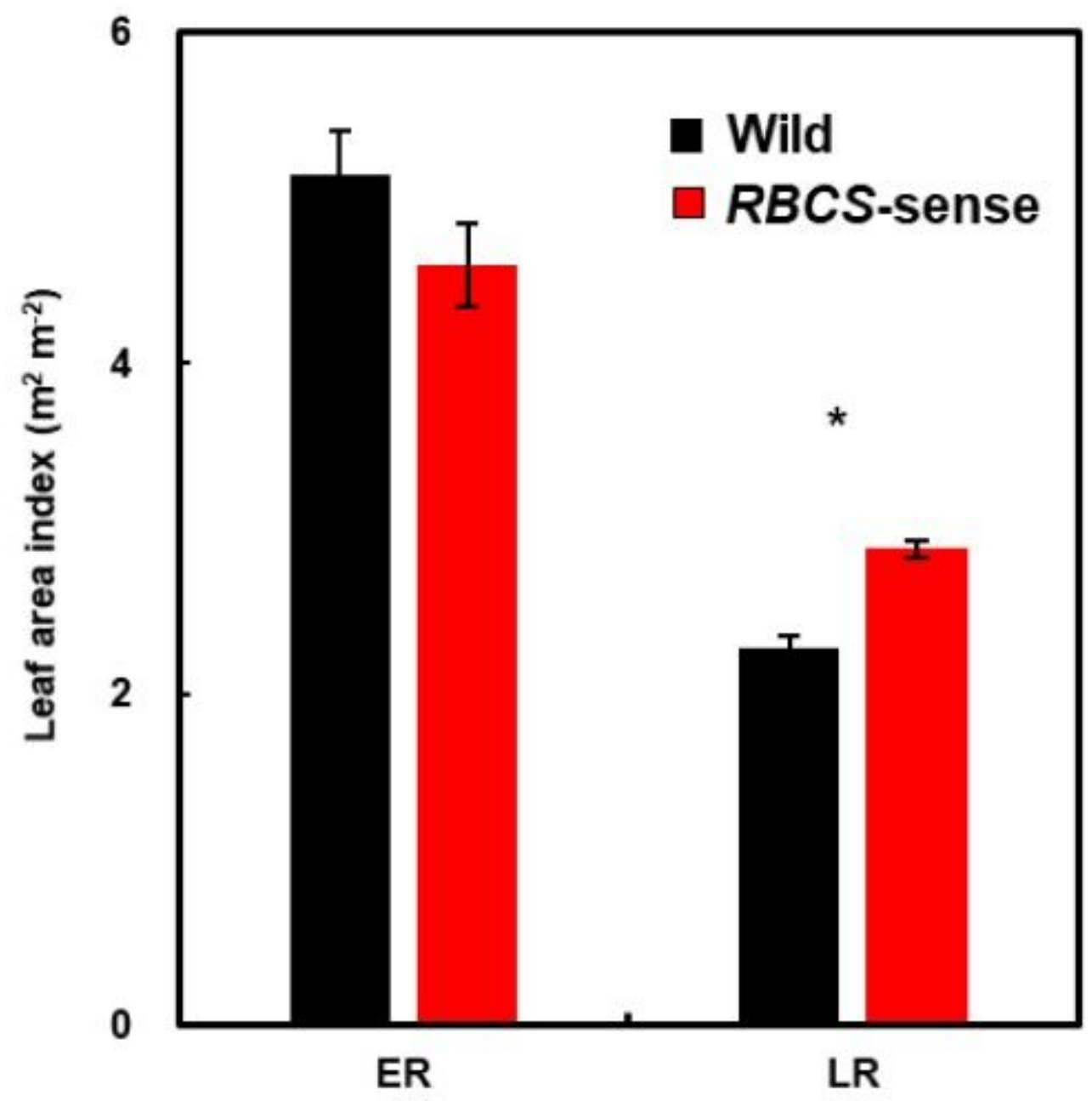

Figure 6

Changes in the leaf area index between $10 \mathrm{DAH}$ in early and $49 \mathrm{DAH}$ in late ripening stages in the plots applied with $15 \mathrm{~g} \mathrm{~N} \mathrm{~m}-2$ fertilizer. Mean values \pm the standard error of three independent plots are indicated. ${ }^{*} p<0.05$ between the wild-type and RBCS-sense rice plants using Student's t-test. The wild-type and RBCS-sense rice plants are indicated by black and red bars, respectively. The abbreviations stand as follows: "ER"; early ripening stage, "LR"; late ripening stage, "RBCS-sense"; transgenic rice plants overproducing Rubisco, "Wild"; wild-type rice plants. 


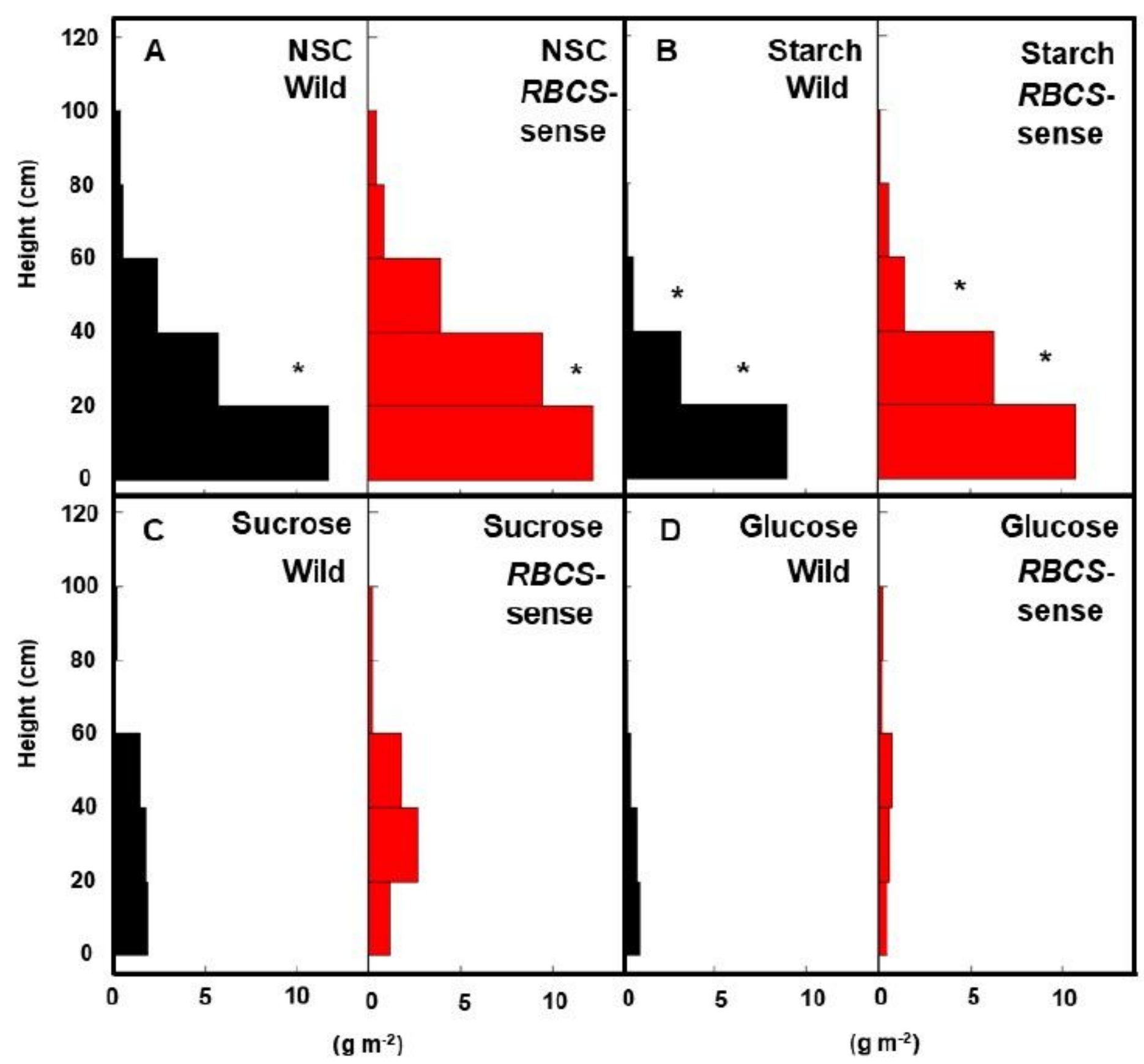

Figure 7

The vertical distribution of the contents of nonstructural carbohydrates (NSC) in the leaf sheaths and stems of wild-type and RBCS-sense rice plants in the canopies at $49 \mathrm{DAH}$ in the late-ripening stage in the plots applied with $15 \mathrm{~g} \mathrm{~N} \mathrm{~m}-2$ fertilizer. The contents of NSC (A) starch (B), sucrose (C), and glucose (D) are indicated. Mean values \pm the standard error of three independent plots are shown. ${ }^{*} p<0.05$ between the wild-type and RBCS-sense rice plants using Student's t-test. The wild-type and RBCS-sense rice plants are represented by black and red bars, respectively. The abbreviations stand as follows: NSC; nonstructural carbohydrates, "RBCS-sense"; transgenic rice plants overproducing Rubisco, "Wild"; wildtype rice plants. 


\section{Supplementary Files}

This is a list of supplementary files associated with this preprint. Click to download.

- 202112036TanakaRBCSSupFile01.pdf

- 202112036TanakaRBCSSupFile02.pdf

- 202112036TanakaRBCSSupFile03.pdf

- 202112036TanakaRBCSSupFile04.pdf 